\title{
DESIGN ON VALIDATION NETWORK OF REMOTE SENSING PRODUCTS IN CHINA
}

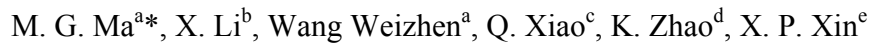 \\ ${ }^{a}$ Cold and Arid Regions Remote Sensing Observation System Experiment Station, CAREERI, Chinese Academy of \\ Sciences, 320 Donggang West Road, Lanzhou, China - mmg@1zb.ac.cn \\ ${ }^{\mathrm{b}}$ Cold and Arid Regions Environmental and Engineering Research Institute (CAREERI), Chinese Academy of \\ Sciences, 320 Donggang West Road, Lanzhou, China - lixin@1zb.ac.cn \\ ${ }^{\mathrm{c}}$ Huailai Remote Sensing Comprehensive Experimental Station, Institute of Remote Sensing and Digital Earth, Chinese \\ Academy of Sciences, No.9 Dengzhuang South Road, Haidian District, China - xiaoqing@irsa.ac.cn \\ d Jingyuetan Remote Sensing Experimental Station, Northeast Institute of Geography and Agroecology, Chinese \\ Academy of Sciences, 3195 Weishan Road, Changchun, China - zhaokai@neigae.ac.cn \\ ${ }^{\mathrm{e}}$ Hulunber Grassland Ecosystem Observation and Research Station, Institute of Agricultural Research and Regional \\ Planning, CCAS, Zhongguancun 12 South Main Street, Haidian District, China - xxp@mail.caas.net.cn
}

KEY WORDS: validation, validation network, remote sensing, remote sensing products, China

\begin{abstract}
:
Validation is important assurance for the usage of remote sensing products. This paper introduces the design of a planning Validation network of Remote sensing Products in China (VRPC). VRPC is planning to incorporate more than 10 experimental stations relating to remote sensing observation. The observation fields of these stations need include typical land surface types as possible. VRPC will be realized step by step. In the first stage, four stations that have better remote sensing observation basis are incorporated. They are Heihe Remote Sensing Comprehensive Experimental Station, Huailai Remote Sensing Comprehensive Experimental Station, Jingyuetan Remote Sensing Experimental Station, Hulunber Grassland Ecosystem Observation and Research Station. In this paper, the over goal of VRPC was introduced firstly. Then the basic selection principles of the observation sites were set down especially for the validation of the remote sensing products. The layout scheme of each observation site was preliminarily designed for various types of products with different spatial resolutions. It is the key problem to realize the combination of observation and research among all the stations. Therefore the unified observation system and operating rules are necessary, which can increase the comparability and consistency of the observation data. Multi-year measurements ensure that inter-annual validity of land products can be assessed in China. 2013 is the first measurement year of the VRPC. Some joint observation plans will be performed in this summer. The validation products mainly include Leaf Area Index \& FPAR, NPP \& GPP, Land Surface Temperature, Evapotranspiration, and so on. The observation sites of VRPC are open and hope more cooperation and exchange in the world.
\end{abstract}

\section{INTRODUCTION}

More and more earth observation satellites had launched recently along with the development of the remote sensing technologies (Wang, 2006). The new sensors were used, which afford a large number of researches to produce abundant remote sensing products. New remote sensing retrieval algorithms have been emphasized by the current studies. More and more works had been launched to produce the long time series and global or regional coverage remote sensing products (Ma, 2012). For example, MODIS products are a typical representative (http://modis.gsfc.nasa.gov/data/dataprod/).

The validation of the remote sensing products is an important procedure before the application of these products (Liang, 2004). The Working Group on Calibration and Validation (WGCV) was established as early as 1984 . The validation was defined by WGCV as the process of assessing, by independent means, the quality of the data products derived from the system outputs (Justice, 2000). The validation activities are defined as a means by which independent field, airborne, and other satellite data will be collected and used to assess the quality of remote sensing products (Morisette, 2002).

Some validation plans were made and implemented globally and regionally. For example, BigFoot was initiated in 1999, which was relatively earlier plan. It aims to provide validation of MODLand (MODIS Land Science Team) science products, including land cover, leaf area index (LAI), fraction absorbed photosynthetic active radiation (fAPAR), and net primary production (NPP) (Cohen, 1999). Validation of Land European Remote Sensing Instruments (VALERI) was initiated by European Space Agency (ESA) in the beginning of 21 century. It aims to validate global land surface remote sensing products derived from sensors of MODIS, VEGETATION, MERIS, POLDER and AVHRR. The products mainly include albedo, vegetation coverage, LAI/FPAR, vegetation indexes (Justice, 2000). The Land Product Validation (LPV) was established by the Committee of the Earth Observation Satellites (CEOS) for proposing a consistent strategy as well as dedicated methods and tools for the validation and intercomparison of land biophysical products. It is a subgroup of WGCV. It tries to formulate the standard guidelines and specifications for the validation of land surface products and promote the data sharing and exchange of the in-suit observation data (Morisette, 20se06). The above validation studies mainly use the in-suit point observations to validate and evaluate the estimation accuracy of the remote sensing products. The scale and scale effects are the key scientific problems, which is the most important methodologies for up-scaling the field observation data to the moderate resolution pixels (Wu, 2009).

Even though a lot of efforts were pushed towards solving key scientific problems of this topic, because of the insufficient study of the validation of remote sensing products and the lack

\footnotetext{
* Corresponding author, mmg@1zb.ac.cn, +86 9314967250.
} 
of the validation theories and practical methods, the validation works are relatively delayed compared with the algorithm development of the remote sensing retrieval. This limits the further applications of remote sensing data and products (Zhang, 2010).

Some newly developed and advanced observation methods like wireless sensor network (WSN) and footprint observation were used recently, which would promote the scale effect researches. For example, tens or more than one hundred nodes with automatic, intelligent, and remote-controllable sensors are set up in region of $5 * 5 \mathrm{~km}$ according to the spatial heterogeneity of the land surface parameters (Jin, 2012). These high-level, highdensity, and automatic observation data can be used to measure the spatial distribution characteristics of eco-hydrological parameters (e.g. soil, temperature, LAI) and develop the scale transform and validation methods (NRC, 2010). The observations of Eddy Covariance (EC), Large Aperture Scintillometer (LAS), Cosmic-Ray Soil Moisture/Snow Observing System (COSMOS) cover a certain areas, which can reach footprints within hundreds to thousands meters (Song, 2012; Jia, 2012; Liu, 2013).

Some special experiments were performed for the validation in the above plans. But these experiments are regional and temporary. Some fixed sites can be used from existing networks such as AERONET (Holben, 1998), FLUXNET (Baldocchi, 2001), and IMSN (Dorigo, 2011). The underlying surface types of these sites normally include most of the typical land covers. The data from these sites are continuous and comparable because of the uniform observation standards and data formats. But, on the other hand, these sites are not designed especially for the validation of remote sensing products, it is difficult to meet the requirement of the node installation strategy toward the scale transform and scale effect analysis.

Here we describe the design of the validation network of remote sensing products in China (VRPC). Firstly, the basic thought and frame were discussed for this network. Then we introduced the four stations involved in this network in the first stage. Lastly we give the initial designs of the operation method and observation standards for the collaborative observation.

\section{BASIC THOUGHT OF VRPC}

Figure 1 shows the frame of VPRC, which include four basic elements. The first element is the design and construction of the observation stations and sites. The stations would be selected according to several principles. The existing bases and resources with remote sensing product validation need be considered firstly. The sites involved in the station need have adequately typical and representative, which are also relatively heterogeneous over an enough area. The installation of observation systems must fully consider the spatial distribution characteristics of the underlying surfaces. In other words, the prior knowledge of the key parameters of the sites' land surface need be acquired and the installation strategy need be optimized based on the prior knowledge (Jin, 2012).

The validation stations can be divided into two main types. The first types are core sites, which are set up especially for the validation of remote sensing products. These sites normally have the special observation techniques such as unmanned aerial vehicle, ground-base remote sensing platforms, and wireless sensors network (WSN). The simultaneous satelliteairborne-ground experiment, ground-base remote sensing control experiment, intensive ground experiment can be launched periodically. The theories and methodologies of the scale transform and validation are studied based on these thematic experiments. The second types are based on the other existing observation networks, such as Chinese Ecosystem Research Network (CERN), Chinese Terrestrial Ecosystem Flux Research Network (ChinaFLUX), and Special Environment and Disaster Network (SEDN). The sites of these networks are set up for special scientific aims. Based on their existing observation base and systems, some improvements can be processed for the demands of remote sensing validation. Then these sites can perform some continuous and fixed observation items. The obtained data are normally used to validate the remotes sensing products directly based above theories and methodologies.

Some validation standards and guidelines of the remote sensing products are studying and formulating by a special project. These standards and guidelines can conduct the construction of the sites and collaborative observation of the core sites and other networks' sites. In turn, the results of applications and theory or methodology studies can be fed back to the makers to improve standards and guidelines.

Some operating and management mechanisms are also needed to formulate for VRPC. Theses mechanisms include in-suit observation guidelines, data processing guidelines, data quality control guidelines, data archiving guidelines, and data sharing regulations, which will be discussed by administrative and technological staffs of these core sites.
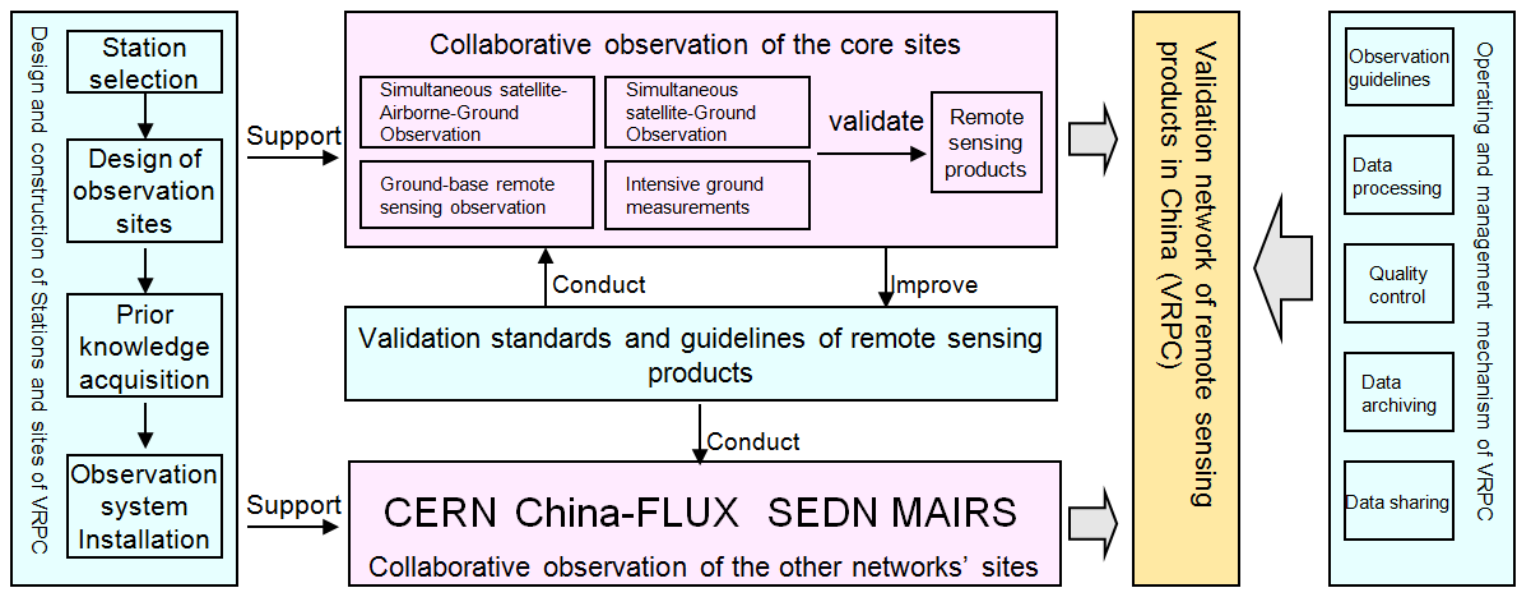

Figure 1. Frame of VRPC 


\section{CORE SITES OF VRPC}

After comprehensive consideration of the local characteristics, underlying surface representative, infrastructures and observation facilities, we plan to reform and construct around 12 observation fields distributed in seven areas in China as the core observation fields of the national remote sensing products validation network, as distributed in figure 2. During the first period of project execution (2012-2014), the project plant to bring four remote sensing stations with the best infrastructures and observation facilities into the remote sensing national validation network, as a pilot for networking collaborative experiments of satellite-airborne-ground synchronous observation and validation of remote sensing products.

According the characteristics of some typical underlying surfaces at every validation region, setting 1-3 standard observation fields with $3 \mathrm{~km} \times 3 \mathrm{~km}$ for remote sensing products validation, some of regions can be set with an area of $2 \mathrm{~km} \times 2 \mathrm{~km}$, and some observation fields that used for validating the soil moisture inverted by passive microwave can be set with an area of $25 \mathrm{~km} \times 25 \mathrm{~km}$. The observation fields of three remote sensing stations that started during the first phase of the project, includes oasis cropland and alpine steppe in the northwest region, cropland in the northern region, cropland and forest in the northeast region of China. The information and function of observation field showed as table 1 .

For every standard observation field that planned to be built, we used the regional multi-resolution satellite images and ground survey to draw the background values of observed elements for the target area, and determine the specific location of these standard observation fields. Meanwhile, with all types of prior knowledge of the experiment fields, we used the layout optimization approaches of heterogeneous pixel scale from the first research part of the project to design all elements of ground observation systems in the experiment fields. After that, we deployed observation nodes and facilities. The observation systems will use multi-scales nested layout mode (i.e. sensor network (with $10 \mathrm{~km}^{2}$ scale), Large Aperture Scintillometer (with $1 \mathrm{~km}^{2}$ scale), eddy covariance (with $100 \mathrm{~m}^{2}$ scale), ground-based remote sensing (with $1 \mathrm{~m}^{2}$ scale) and in situ, etc.) to cope with validation of remote sensing products with various resolutions.

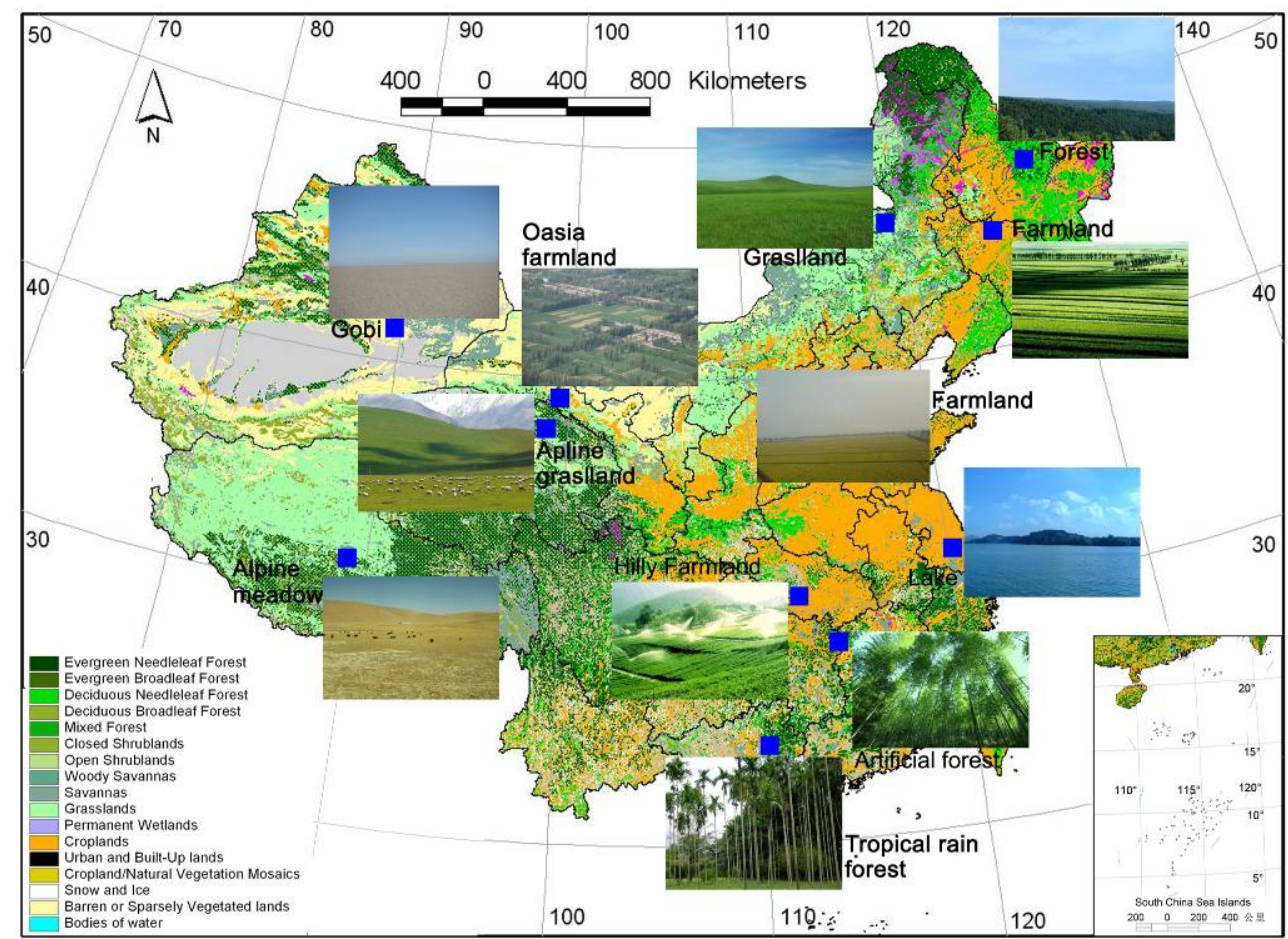

Figure 2. Core sites and their vegetation types of VRPC

Table 1. Core observation sites and their functions of VRPC during the first period

\begin{tabular}{|c|c|c|c|c|c|}
\hline No & zoning & $\begin{array}{l}\text { Underlying } \\
\text { surface }\end{array}$ & Validated variables & Validation methods & Remote sensor \\
\hline 1 & \multirow[t]{2}{*}{$\begin{array}{l}\text { Northwest } \\
\text { Region }\end{array}$} & $\begin{array}{l}\text { Oasis } \\
\text { farmland }\end{array}$ & $\begin{array}{l}\text { vegetation physiological } \\
\text { parameters }^{(1)} \text {, radiation } \\
\text { and energy parameters }^{(2)}, \\
\text { hydrological parameters } \\
\text { aerodynamic roughness }\end{array}$ & $\begin{array}{l}\text { sensor network, satellite-aircraft-ground } \\
\text { synchronous observation experiments }{ }^{\circledR} \text {, } \\
\text { satellite -ground synchronous observation } \\
\text { experiments, ground strengthen } \\
\text { observation, flux towers, high precision } \\
\text { field differential measurement, lysimeter }\end{array}$ & $\begin{array}{l}\text { visible and near } \\
\text { infrared (VNIR), } \\
\text { thermal infrared } \\
\text { (TIR), active } \\
\text { microwave and } \\
\text { laser radar }\end{array}$ \\
\hline 2 & & $\begin{array}{l}\text { Alpine } \\
\text { grassland }\end{array}$ & $\begin{array}{l}\text { vegetation physiological } \\
\text { parameters, radiation and } \\
\text { energy parameters, } \\
\text { hydrological parameters, }\end{array}$ & $\begin{array}{l}\text { sensor network, satellite-aircraft-ground } \\
\left.\text { synchronous observation experiments }{ }^{(}\right) \\
\text {satellite -ground synchronous observation }\end{array}$ & $\begin{array}{l}\text { VNIR, TIR, } \\
\text { passive } \\
\text { microwave, laser } \\
\text { radar }\end{array}$ \\
\hline
\end{tabular}




\begin{tabular}{|c|c|c|c|c|c|}
\hline & & & $\begin{array}{l}\text { snow cover parameters } \\
\text { aerodynamic roughness, } \\
\text { satellite original images, } \\
\text { DOM, DLG and DEM }\end{array}$ & $\begin{array}{l}\text { experiments, ground strengthen } \\
\text { observation, flux towers, high precision } \\
\text { field differential measurement }\end{array}$ & \\
\hline 3 & \multirow[t]{2}{*}{$\begin{array}{l}\text { Northeast } \\
\text { Region } 1\end{array}$} & Farmland & $\begin{array}{l}\text { Vegetation physiological } \\
\text { parameters, radiation and } \\
\text { energy parameters, } \\
\text { hydrological parameters } \\
\text { and aerodynamic } \\
\text { roughness }\end{array}$ & $\begin{array}{l}\text { Sensor network, satellite-aircraft-ground } \\
\text { synchronous observation experiments, } \\
\text { satellite -ground synchronous observation } \\
\text { experiments, ground strengthen } \\
\text { observation, vehicle observation platform } \\
\text { and flux tower }\end{array}$ & $\begin{array}{l}\text { VNIR, TIR and } \\
\text { passivity } \\
\text { microwave }\end{array}$ \\
\hline 4 & & Forest & $\begin{array}{l}\text { LAI VI、NPP、 } \\
\text { Fcover、AOD、ES } \downarrow \text {, } \\
\text { EL } \downarrow \text { Albedo }\end{array}$ & $\begin{array}{l}\text { satellite-aircraft-ground synchronous } \\
\text { observation experiments, satellite -ground } \\
\text { synchronous observation experiments, } \\
\text { ground strengthen observation, flux tower }\end{array}$ & $\begin{array}{l}\text { VNIR and laser } \\
\text { radar }\end{array}$ \\
\hline 5 & \multirow{3}{*}{$\begin{array}{l}\text { Northeast } \\
\text { Region } 2\end{array}$} & Farmland & $\begin{array}{l}\text { Vegetation physiological } \\
\text { parameters, radiation and } \\
\text { energy parameters, } \\
\text { hydrological parameters }\end{array}$ & $\begin{array}{l}\text { Sensor network, satellite-aircraft-ground } \\
\text { synchronous observation experiments, } \\
\text { satellite -ground synchronous observation } \\
\text { experiments, ground strengthen } \\
\text { observation, vehicle observation platform } \\
\text { and flux tower }\end{array}$ & VNIR, TIR \\
\hline 6 & & Forest & $\begin{array}{l}\text { LAI、VI、NPP、 } \\
\text { Fcover、AOD、ES } \downarrow \\
\text { EL } \downarrow \text { Albedo }\end{array}$ & $\begin{array}{l}\text { satellite-aircraft-ground synchronous } \\
\text { observation experiments, satellite -ground } \\
\text { synchronous observation experiments, } \\
\text { ground strengthen observation, flux tower }\end{array}$ & VNIR, TIR \\
\hline 7 & & Grassland & $\begin{array}{l}\text { Vegetation physiological } \\
\text { parameters, radiation and } \\
\text { energy parameters and } \\
\text { hydrological parameters }\end{array}$ & $\begin{array}{l}\text { Sensor network, airship-satellite-ground } \\
\text { synchronous observation experiments, } \\
\text { ground strengthen observation, flux tower } \\
\text { and high precision field differential } \\
\text { measurement }\end{array}$ & $\begin{array}{l}\text { VNIR, TIR, } \\
\text { active microwave } \\
\text { and laser radar }\end{array}$ \\
\hline 8 & \multirow{3}{*}{$\begin{array}{l}\text { Northern } \\
\text { China }\end{array}$} & Farmland & $\begin{array}{l}\text { Vegetation physiological } \\
\text { parameters }^{(1)}, \text { radiation } \\
\text { and energy parameters }^{(2)} \\
\text { and hydrological } \\
\text { parameters }^{(3)}\end{array}$ & $\begin{array}{l}\text { Sensor network, vehicle observation } \\
\text { platform, airship-satellite-ground } \\
\left.\text { synchronous observation experiments }{ }^{(}\right) \\
\text {ground strengthen observation, flux tower } \\
\text { and high precision field differential } \\
\text { measurement, lysimeter }\end{array}$ & $\begin{array}{l}\text { VNIR, TIR, } \\
\text { active microwave } \\
\text { and laser radar }\end{array}$ \\
\hline 9 & & $\begin{array}{l}\text { Water } \\
\text { area }\end{array}$ & $\begin{array}{l}\text { Water temperature, } \\
\text { radiation and energy } \\
\text { parameters }\end{array}$ & Sensor network & VNIR, TIR \\
\hline 10 & & Grassland & $\begin{array}{l}\text { Vegetation physiological } \\
\text { parameters }^{(1)}, \text { radiation } \\
\text { and energy parameters } \\
\text { and hydrological } \\
\text { parameters }^{(3)}\end{array}$ & $\begin{array}{l}\text { Sensor network, vehicle observation } \\
\text { platform, airship-satellite-ground } \\
\left.\text { synchronous observation experiments }{ }^{(}\right) \\
\text {ground strengthen observation, flux tower } \\
\text { and high precision field differential } \\
\text { measurement }\end{array}$ & $\begin{array}{l}\text { VNIR, TIR, } \\
\text { active microwave } \\
\text { and laser radar }\end{array}$ \\
\hline
\end{tabular}

(1) vegetation physiological parameters: Vegetation Index(VI), Leaf Area Index(LAI), Vegetation coverage (Fcover), chlorophyll content, phenological period, Fraction of Photosynthetically Active Radiation(FPAR), Net Primary Productivity(NPP) (2) Radiation and energy parameters: Albedo, Aerosol Optical Depth(AOD), Downward short-wave radiation(ES $\downarrow$ ), Downward longwave radiation(EL $\downarrow$ ), Land Surface Temperature(LST), emissivity, Net Radiation $\left(\mathrm{R}_{\mathrm{net}}\right)$

(3)Hydrological parameters: Soil Moisture(SM), Evapotranspiration (ET)

(4) Satellite-aircraft-ground synchronous observation experiments were mainly promoted by the second research parts of this project.

(5) Snow cover parameters: Snow area, Snow water equivalent

\section{INTRODUCTION ON THE VALIDATION STATIONS OF VRPC IN THE FISRT STAGE}

\subsection{Heihe Remote Sensing Experimental Station (Heihe station)}

Heihe Remote Sensing Experimental Station (HHRSTS), the short name of Heihe station, was founded in 2009 by Cold and Arid Regions Environmental and Engineering Research Institute (CAREERI), Chinese Academy of Sciences (CAS). This station is located at the Ganzhou District, Zhangye City $\left(100^{\circ} 29^{\prime}, 38^{\circ} 50^{\prime}\right)$ in the middle reaches of the Heihe River
Basin and surrounded by the landscapes of artificial oasis, lowmountain desert belt, and gobi, desert and wetland. The station is the ecological and hydrological experiment base and validation base of the quantitative remote sensing products for Chinese cold and arid regions. The long-term remote sensing monitoring on the ecological and hydrological processes in the cold and arid regions is performed for the development of remote sensing forward model and inversion models. The pixelscale experimental sites are constructed for validation of a series present and future remote sensing products at home and abroad. The main field observation methods include irregular flights by manned and unmanned aerial vehicles, ground-base 
remote sensing, wireless sensor network, footprint observation (e.g. EC, LAS, COSMOS, GammeMONitor).

\subsection{Huailai Remote Sensing Comprehensive Experimental Station (Huailai Station)}

Huailai Remote Sensing Test Station (HLRSTS) was founded in 2004 by Institute of Remote Sensing Application(IRSA), Chinese Academy of Sciences (CAS). This station is located at the Huailai county, Hebei Province $\left(115^{\circ} 46^{\prime} 59.569^{\prime \prime} ; 40^{\circ}\right.$ $20^{\prime}$ 55.093) in the middle of the Yan-huai Basin and surrounded by the Yanshan mountain, farmland, Guanting reservoir, and Yeyahu wetland. The station is the remote sensing fundamental experiment base and validation base of the quantitative remote sensing products. Several plant(tree and crops)sample plot and the tower measurement platform has been established inside the test station. The long-term remote sensing monitoring on the ecological, energy and hydrological processes in KM satellite pixel-scale is performed for the development of remote sensing forward model and inversion models by ground-base and tower-base remote sensing measurement, wireless sensor network, footprint observation (e.g. EC, LAS).

\subsection{Jingyuetan Remote Sensing Experimental Station (Jingyuetan Station)}

Jingyuetan Remote Sensing Experimental Station was established by three Changchun institutes of Chinese Academy of Sciences (CAS) in 1985. It is located at longitude $125^{\circ} 26^{\prime} 41.45^{\prime \prime} \mathrm{E}$, latitude $43^{\circ} 47^{\prime} 24.55^{\prime \prime} \mathrm{N}$ in the temperate zone of China. Jingyuetan station mainly works toward the Jingyuetan National Forestry Park and farmlands, waters and urban lands around the park. Jingyuetan station carries out researches of efficient data processing techniques to achieve effective management and application of remote sensing data and establish a validity system for multi-scale, multi-temporal, and multiple remote sensing products. It is fully equipped with ground-based remote sensing observation facilities (e.g. spectrometer and microwave radiometer), mobile integrated remote sensing observation platform, and laboratories for spectral and microwave measurements.

\subsection{Hulunber Grassland Ecosystem Observation and Research Station (Hulunber Station)}

Hulunbeier Grassland Ecosystem Observation And Research Station was founded in 1997 by the Institute of Natural Resources and Regional Planning, Chinese Academy of Agricultural Sciences, at the recommendation of Academician LiBo. The station is located at the Xiertala District, Hailaer Area in Hulunbeier City under geographic coordinates between

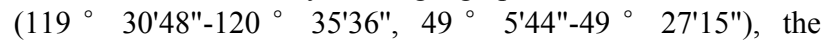
northeast of the Inner Mongolia Autonomous Region, of which the eastern edge is approached the Daxinganling western foothills. The landscape from east to west is gradually through the meadow steppe into the typical semi-arid steppe zone, along with the formation of climatic eco-geographical gradient. The station is the ecological and grassland biological experiment base and validation base of the quantitative remote sensing products for Chinese continental monsoon climatic regions. The long-term remote sensing monitoring on the ecological and grassland biological processes is performed for the development of remote sensing models. The pixel-scale experimental sites are also constructed for validation of a series present and future remote sensing products at home and abroad. The main field observation methods include footprint observation, carbon cycle observation, and ground-base ecological remote sensing, with the future prospect of establishing a complete equipment for wireless sensor network in the next few years.

\section{COLLABORATIVE OBSERVATION OF THE CORE SITES DURING 2013}

According to the above initial shaped specification draft of operation and observation for national remote sensing products validation network, we will conduct the satellite-ground synchronous observation experiments at multi-observation fields or multi-sites regularly during the first years of the project, thus forming the collaborative observation ability for validating the same remote sensing product in the three remote sensing stations, and gradually improving the collaborative observation mechanisms, and initially implementing the prototype of national remote sensing validation network at last. In view of the main remote sensing products produced by domestic and overseas in the current and next year (Table 1), we conducted the collaborative observations uniting these core observation sites. After accomplished the data processing and quality controlling, the multi-scale ground observation data set will be produced. Based on the validation schemes designed by this project, after the scale transformation of the ground observations, different resolutions of the "truth value" with pixel scale will be produced. Through collecting the above satellite products meanwhile, the validation of products will be conducted.

It can be divided into various types of experiments: satelliteaircraft-ground synchronous observation experiments, satelliteground synchronous observation experiments (conducted collaboratively at all sites), ground-based remote sensing observation experiment (conducted individually at each site)and ground strengthen observations, etc. On the basis of sufficiently considering the underlying surface and phenological characteristics at each observation field and according to the key variables needed to be validate in Table 1, we specifically designed the periods, elements, schemes of the observations, and the collection plans of satellite products during the above experiments. To facilitate the further comparison research, each observation fields try to collaborative observation for the same element.

\section{CONCLUSION}

Validation of the remote sensing products has been a key process before application of them. Several validation plans have been launched by occident. A new validation activity, VRPC, was designed for regional application in China. Some conclusions from VRPC are summarized as follow.

(1) The frame of VRPC has been established (Figure 1). Four component elements are involved in this frame.

(2) Some core sites have been selected after full consideration of the representation of the underlying surfaces. The available remote sensing products for each site are also selected according to the observation base and land surface types.

(3) The VRPC will be constructed by several stages. Four existing stations with better conditions have been selected in the first stage.

(4) A collaborative observation plan by the core sites is planned to perform during the summer of 2013.

In this paper the design of VRPC is preliminary and simple. More works need to make in the following items. 
(1) The technical criteria for field site selection and arrangement of remote sensing product validation need to be prepared before the construction of core sites.

(2) The validation standards and guidelines of the remote sensing products need be finished early, which are important base for the collaborative observation in 2013.

(3) The operating and management mechanisms of VRPC need be discussed by the core sites. It is the important undertaking to conduct the data processing and data sharing after the observation experiment.

\section{Acknowledgements}

This research was funded by the national high-tech program (863) of China (grant number: 2012AA12A305; 2013AA12A301).

\section{References}

Wang, X. M., Gao, F., Ma, M. G., 2006. Introduction of Global Land Imaging Satellites. Remote Sesning Technology and Application, 21(6), pp. 607-611. (in Chinese)

Zhang, R H, Tian, J, Li, Z L, et al., 2010. Principles and methods for the validation of quantitative remote sensing products. Science China-Earth Science, 53(5), pp.741-751.

Ma, M. G., Song, Y., Wang, X. F., et al., 2012. Development Status and Application Research of the time series remote sensing data products Based on AVHRR, VEGETATION and MODIS. Remote Sensing Rechnology and Application, 27(5), pp. 663-670. (in Chinese)

Cohen, W.B. and C. O. Justice. 1999. Validating MODIS terrestrial ecology products: linking in situ and satellite measurements. Remote Sensing of Environment, 70, pp.1-4.

Liang S. L., 2004. Quantitative Remote Sensing of Land Surfaces. John Wiley \& Sons, New Jersey, pp.431-433.

Baret, F, Morissette, J T, Fernandes R A, et al., 2006. Evaluation of the Representativeness of Networks of Sites for the Global Validation and Intercomparison of Land Biophysical Products: Proposition of the CEOS-BELMANIP. IEEE Transactions on Geoscience and Remote Sensing, 44(7), pp. 1794-1803.

Justice C, Belward A., Morisette J., et al., 2000. Developments in the 'validation' of satellite sensor products for the study of the land surface. International Journal of Remote Sensing, 21(17), pp. 3383-3390.

Morisette, J. T., Baret F., Privette, J. L., et al., 2006. Validation of Global Moderate-resolution LAI Products: a Framework
Proposed Within the CEOS Land Product Validation Subgroup. IEEE Transactions on Geoscience and Remote Sensing, 44(7), pp. 1804-1817.

Morisette, J. T., Privette J.L., and Justice C.O., 2002. A framework for the validation of MODIS land products, Remote Sensing of Environment, 83 (1-2), pp. 77-96.

Wu H. and Li Z. L., 2009. Scale Issues in Remote Sensing: A Review on Analysis, Processing and Modeling. Sensors, 9, pp. 1768-1793.

Jin R., Li X., Yan B. P., et al., 2012. Introduction of Ecohydrological Wireless Sensor Network in the Heihe River Basin Advances in Earth Science, 2012, 27(9), pp. 993-1005. (in Chinese)

NRC, 2010. Committee on the Review of Water and Environmental Research Systems (WATERS) Network, National Research Council. Review of the WATERS Network Science Plan. National Academies Press, pp. 88

Song Y, Wang J M, Yang K, et al., 2012. A Biophysical based Surface Resistance Model to Estimate Latent Heat Flux Using Remotely Sensed Data. International Journal of Applied Earth Observation and Geoinformation, 17, pp. 76-84.

Liu S. M., Xu Z.W., Zhu Z.L., et al., 2013. Measurements of evapotranspiration from eddy-covariance systems and large aperture scintillometers in the Hai River Basin, China. Journal of Hydrology, 487, pp. 24-38.

Jia, Z., Liu S. M., Xu Z. W., et al., 2012. Validation of remotely sensed evapotranspiration over the Hai River Basin, China. Journal of Geophysical Research-atmospheres, doi:10.1029/2011JD017037.

Holben B. N., Eck T. F., Slutsker I., et al., 1998 AERONET - A Federated Instrument Network and Data Archive for Aerosol Characterization. Remote Sensing of Environment, 66, pp.1-16.

Baldocchi D., Falge E., Gu L. H., et al., 2001. FLUXNET: A New Tool to Study the Temporal and Spatial Variability of Ecosystem-Scale Carbon Dioxide, Water Vapor, and Energy Flux Densities. Bulletin of the American Meteorological Society, 82(11): 2415-2434.

Dorigo W. A., Wagner W., Hohensinn R., et al., 2011. The International Soil Moisture Network: a Data Hosting Facility for Global in Situ Soil Moisture Measurements. Hydrology and Earth System Sciences, 15: 1675-1698. 